\title{
Comparative Study of Space Vector Controlled Three Phase-Six Phase Direct and Indirect Matrix Converter for Six Phase Induction Motor Drive
}

\author{
${ }^{* 1}$ Shubhangi A. Yerkal, ${ }^{2}$ M. V. Aware, ${ }^{3}$ B. S. Umre, ${ }^{4}$ Manoj Waghmare \\ 1,2,3,4 Department of Electrical Engineeing, Visvesvaraya National Institute of Technology, Nagpur, India \\ Email:shubhangi.yerkal@gmail.com,mvaware@eee.vnit.ac.in,bsumre@eee.vnit.ac.in, \\ manoj10waghmare@gmail.com
}

Received: 10th October 2019, Accepted: 31st January 2020, Published: 29th February 2020

\begin{abstract}
This literature gives a comparative study of multiphase (six phase) matrix converter (Direct and Indirect) feeding power to six-phase symmetrical induction motor. These converters are modulated by Space Vector Modulation technique with different modulation index 0.6 and 0.8 and behavior of six phase symmetrical induction motor is analyzed. Six-phase Induction Motor is modelled and both the converters are analyzed in MATLAB/Simulink environment. The separate simulation results of direct and indirect matrix converter fed induction motor is presented consists of output line voltage, phase voltage, speed, torque.
\end{abstract}

\section{Keywords}

Six-Phase Direct Matrix Converter, Six-Phase Indirect Matrix Converter, Space Vector Modulation, Six Phase Symmetric Induction Motor.

\section{Introduction}

In the industrial applications, multiphase drives have been receiving increased attention due to their several advantages over the traditional three-phase induction machines such as reduced per phase currents, torque pulsation at a higher frequency, the possibility of controlling more than one motors when supplied by one multiple converter, higher reliability. Because of this features multiphase motor drives use for high power and medium voltage drive applications [1]. Six phase motor drives as the multiphase motor drive considered as a viable solution because they are the multiple of the existing three-phase numbers. Six-phase induction motor can be configured as symmetrical and asymmetrical motors. Symmetrical six-phase motor consists of six windings with $60^{\circ}$ phase displacement. In asymmetrical type, two sets of balanced three-phase windings are displaced by $30^{0}$ with isolated neutral point [2].

In earlier days, back-to-back converter that is three-phase rectifier and multiphase inverter was used to drive asynchronous machines with a bulky interlinked energy storage element in between. These is the main limitation of back-to-back converters because the weight of the energy storage element is almost $30 \%$ of the converter. Therefore, in recent days multiphase matrix converter are used which can convert the constant ac input voltage and constant input frequency into variable ac output voltage and variable frequency [3]. Matrix converter comes up with the drawback of back-to-back, features of matrix converters are i) Bidirectional power flow ii) capacitor free power exchange iii) sinusoidal source current iv) controllable input power factor [4]. Apart from advantages, Matrix converter has some limitations also, such as number of switches are more therefore multistep commutation is required also as there is no dc link capacitor there may be distortion at output voltage hence filter is required between input source and converter [5].

Mainly MC is categorized into two types i) direct matrix converter (DMC) and ii) indirect matrix converter (IMC). DMC works on the principle of single stage conversion while IMC works on the principle of dual-stage AC-AC conversion without associating interlinked storing element [6].

There are different control techniques to implement the matrix converter such as Pulse Width Modulation (PWM), Sinusoidal Pulse Width Modulation, Space Vector Pulse Width Modulation (SVPWM), Space Vector Modulation (SVM), Venturini method, Scalar method (Roy), Carrier-based PWM. A powerful and very elegant method nowadays using is SVM method [7]. SVM is of two types i) Direct SVM and ii) Indirect SVM, Direct SVM is difficult to implement and not flexible. On the other hand, advantage of indirect SVM is that input line current and output phase voltage of matrix converter can control independently [8] and gives maximum output voltage 0.776 without injecting third harmonic component, therefore in this paper indirect SVM (Space Vector Modulation), control technique is used to control the matrix converter [9]. Simulation is done using MATLAB/Simulink software package to compare the performance of three-six phase DMC and three-six phase IMC fed six-phase symmetrical motor, for this simulation, parameters has kept constant.

The paper structure is as follows: II presents the modelling of six-phase DMC, section III presents the modelling of six-phase IMC, SVM technique is presented in section IV, section V presents the mapping of pulses to get the 
pulses for DMC and IMC. Finally, section VI gives the simulation results for both DMC, IMC fed IM, and section VII gives conclusion.

\section{Materials \& Methods}

Direct Matrix Converter

For three-to-six phase DMC each input phase source is directly connected to the each output phase load terminals through the switch, hence it can be say that DMC works on the principal of direct ac-ac conversion. A three-six DMC fed six-phase induction motor is shown in Fig. 1. The output phase voltages are given as,
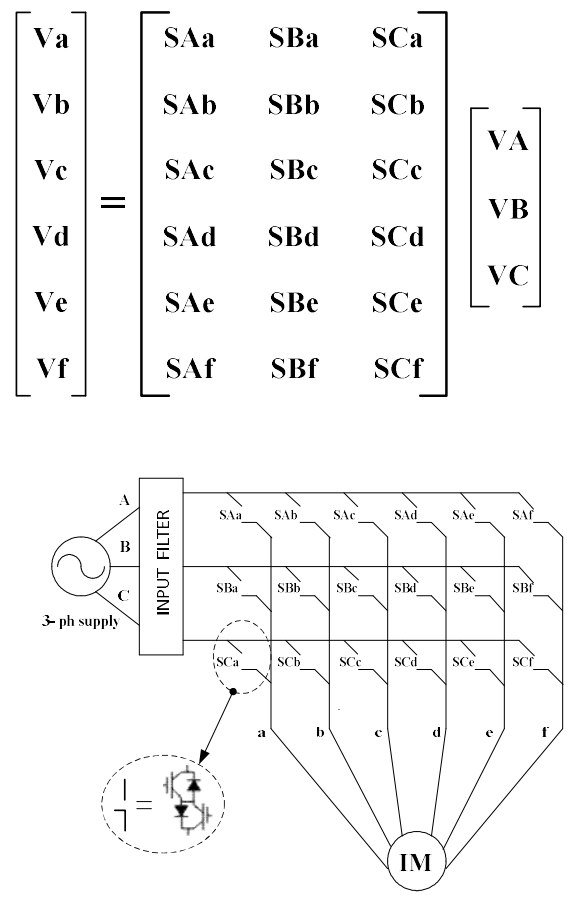

Fig 1: Diagram of Three-to-Six Phase Direct Matrix Converter

$V_{\mathrm{o}}=\mathrm{T} \times V_{\mathrm{i}}$

Where $V_{\mathrm{o}}$ is the output phase voltage and $V_{\mathrm{i}}$ is the input phase voltage. $\mathrm{T}$ is the switching transfer function. The input current is given as,

$$
\left[\begin{array}{c}
\text { IA } \\
\text { IB } \\
\text { IC }
\end{array}\right]=\left[\begin{array}{ccc}
\text { SAa } & \text { SBa } & \text { SCa } \\
\text { SAb } & \text { SBb } & \text { SCb } \\
\text { SAc } & \text { SBc } & \text { SCc } \\
\text { SAd } & \text { SBd } & \text { SCd } \\
\text { SAe } & \text { SBe } & \text { SCe } \\
\text { SAf } & \text { SBf } & \text { SCf }
\end{array}\right]\left[\begin{array}{c}
\text { Ia } \\
\text { Ib } \\
\text { Ic } \\
\text { Id } \\
\text { Ie } \\
\text { If }
\end{array}\right]
$$

Where $I_{\mathrm{i}}$ is the input phase current and $I_{\mathrm{o}}$ is the output phase current. The switching function can be derived as $I_{\mathrm{i}}=\mathrm{T} \times I_{\mathrm{o}}$

$\mathrm{Sij}=1$, Switch ON

$=0$, Switch OFF

Where $i=(A, B, C)$ and $j=(a, b, c)$

\section{Indirect Matrix Converter}

The three-to-six phase indirect matrix converter is designed by cascading a 3-ph rectifier with a 6-ph inverter without associating dc link capacitor; hence, it can be say that IMC works on the principal of virtual ac-dc-ac conversion. Three-to-six IMC is shown in fig 2. 


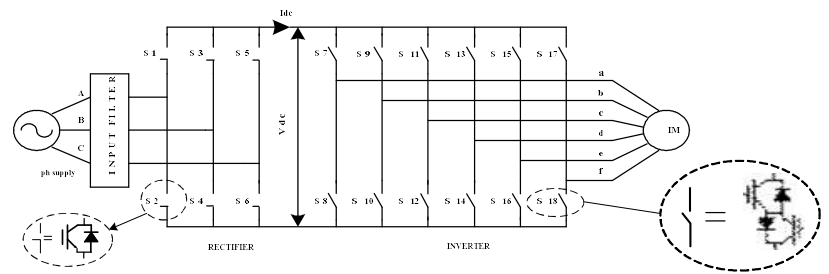

Fig 2: Diagram of Three-to-Six Phase Indirect Matrix Converter

Space Vector Modulation Technique

SVM divides the DMC indirectly into two stages, one is virtual rectifier and other is virtual inverter. SVM provides the independent control of output phase voltage and input line current therefore; switches of DMC can be control by applying the SVM on virtual rectifier and SVM on virtual inverter.

\section{A. SVM on three-phase rectifier side}

There are nine switching states of three phase rectifier out of which six are active input current vectors $\left(I_{1}-I_{6}\right)$ and three are zero vectors (AA,BB,CC).Space vector diagram of rectifier is given in Fig 3. which is obtained by the equation (4).

$I_{\mathrm{i}}=\frac{2}{3}\left(I_{A}+\mathrm{k} I_{\mathrm{B}}+k^{2} I_{\mathrm{C}}\right)$

Where, $\mathrm{k}=\mathrm{e}^{\frac{\mathrm{i} 2}{3}}$

For vector $I_{1}$, switching state is $\mathrm{AB}$ it means that for a phase upper switch is $\mathrm{ON}$ and lower switch is OFF. For $\mathrm{B}$ phase upper switch is OFF and lower switch is ON. C phase it may both upper and lower be either ON or OFF. There are six sectors from 1-6, and each sector is spanned for $60^{\circ}$. Sector 1 is lies between $-30^{0}$ to $30^{\circ}$. From $I_{1}$ to $I_{2}$ only one phase should change its direction similarly for other vectors also.

Duty ratio of the current vectors are given in equations (5)-(7)

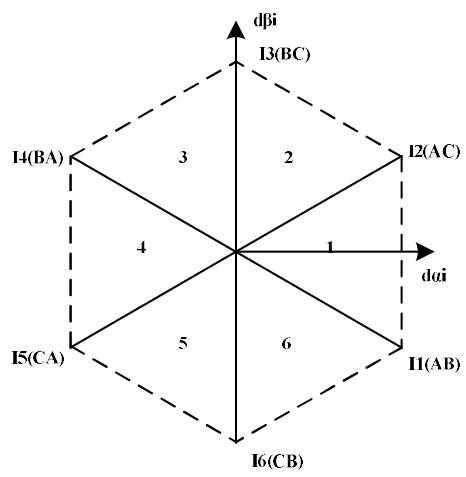

Fig 3: Current Space Vectors of Rectifier Side

$d_{\alpha i}=m_{i} \cdot \sin (\pi / 3-\theta i)$

$d_{\beta i}=m_{i} \cdot \sin (\theta i)$

$d_{0 i}=1-d_{\alpha i}-d_{\beta i}$

Where $m_{i}$ is the modulation index of rectifier stage, which is given by,

$0 \leq m_{i}=I_{i} / I_{d c} \leq 1$

\section{B. SVM on Six Phase Inverter Side}

For six phase inverter there are $2^{6}=64$ output voltage vectors from which 54 are active vectors and 10 are zero vectors. These active vectors form 12 sectors with each spanning $30^{\circ}$ and placed in $\mathrm{x}-\mathrm{y}, \mathrm{d}-\mathrm{q}, 0^{+}-0^{-}$plane obtained by the equations (9)-(11) [10].

$$
\begin{aligned}
& V_{d q}=\frac{2}{6}\left(V_{a}+\mathrm{a} V_{b}+a^{2} V_{c}+a^{3} V_{d}+a^{4} V_{e}+a^{5} V_{f}\right) \\
& V_{x y}=\frac{2}{6}\left(V_{a}+a^{2} V_{b}+a^{4} V_{c}+V_{d}+a^{2} V_{e}+a^{4} V_{f}\right) \\
& V_{0^{+}-0^{-}}=\frac{2}{3}\left(V_{a} \pm V_{b} \pm V_{c} \pm V_{d} \pm V_{e} \pm V_{f}\right)
\end{aligned}
$$

Where, $\mathrm{a}=e^{-j \frac{\pi}{3}}$

To reduce the THD at the output voltage $x-y$ components should be eliminated by selecting the proper vectors and dwell time hence considering only d-q components. Further 64-output voltage vectors are classified into large, medium and short vectors dependent on the length of the vectors which are given by the equations (12)-(15) 


$$
\begin{aligned}
& V_{1}-V_{6}=\sqrt{\frac{2}{6}} V_{d c} 2 \exp \left(\mathrm{j}(\mathrm{k}-1) \frac{\pi}{3}\right) \quad \mathrm{k}=1,2 \ldots 6 \\
& V_{8}, V_{15}-V_{22}, V_{41}-V_{43}, V_{56}-V_{58}=0 \\
& V_{9}-V_{14}, V_{16}-V_{21}, V_{23}-V_{40}, V_{50}-V_{55}, V_{15}-V_{22}, V_{15}-V_{22}=\sqrt{\frac{2}{6}} V_{d c} \exp \left(\mathrm{j}(\mathrm{k}-1) \frac{\pi}{3}\right) \quad \mathrm{k}=1,2 \ldots 6 \\
& V_{44}-V_{49} \& V_{59}-V_{64}=\sqrt{\frac{2}{6}} V_{d c} \sqrt{3} \exp \left(\mathrm{j}(2 \mathrm{k}-1) \frac{\pi}{6}\right) \quad \mathrm{k}=1,2 \ldots 6
\end{aligned}
$$

Where, equation (12) are large vectors, equation (13) are zero vectors, equation (14) are short vectors and equation (15) are medium vectors. That is 6 long vectors, 36 short vectors, 12 medium vectors and 10 zero vectors. The magnitude ratio of long, short and medium vectors are $2: 1: \sqrt{3}$. Using above equations $V_{x y}, V_{d q}$ and $V_{0^{+}-0^{-}}$drawn shown in Fig. 4 and Fig. 5.

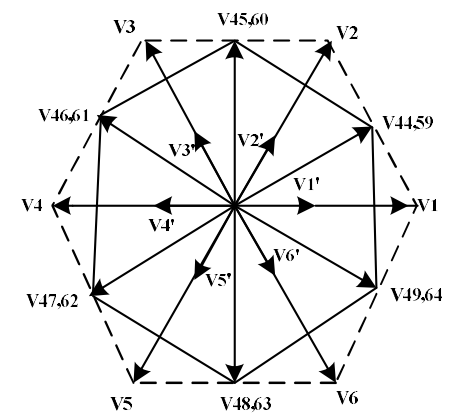

Fig 4: Voltage Space Vector for Inverter in d-q Frame

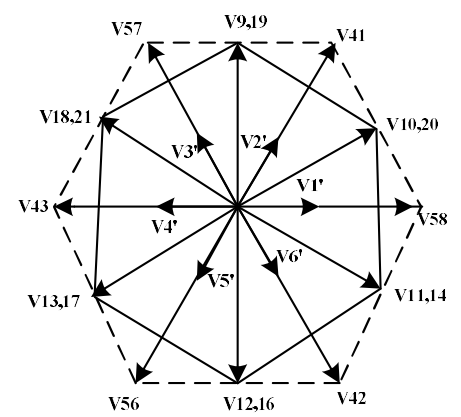

Fig 5: Voltage Space Vector for Inverter in $x-y$ Frame

i) $\boldsymbol{d}-\boldsymbol{q}$

$\mathrm{V} 1$ '=vectors $-9,16,23,29,35,50 \quad \mathrm{~V} 2$ '= vectors $-10,17,24,30,36,51 \mathrm{~V} 3$ '= vectors- $11,18,25,31,37,52$

$\mathrm{V} 4{ }^{\prime}=$ vectors $-12,19,26,32,38,53 \mathrm{~V}^{\prime}$ '= vectors $-13,20,27,33,39,54 \mathrm{~V} 6$ ' $=$ vectors- $14,21,28,34,40,55$

ii) $\mathbf{x}-\mathbf{y}$

$\mathrm{V} 1{ }^{\prime}=$ vectors $-29,32,35,38,45,48 \quad \mathrm{~V} 2{ }^{\prime}=$ vectors $-25,28,52,55,59,62 \quad \mathrm{~V} 3^{\prime}=$ vectors-30, 33, 36, 39, 46, 49

$\mathrm{V} 4{ }^{\prime}=$ vectors $-23,26,50,53,60,63 \quad \mathrm{~V}^{\prime}{ }^{\prime}=$ vectors $-31,34,37,40,44,47 \quad \mathrm{~V} 6{ }^{\prime}=$ vectors- $24,27,51,54,61,64$

Vectors-1, 2, 3, 4, 5, 6, 7, 8, 15, 22 are zero vectors for $\mathrm{x}$-y component

Dwell time for large, medium and short vectors are given in equations (16)-(19)

$$
\begin{aligned}
& t_{l}=\alpha \frac{V_{m \beta} V_{\alpha}-V_{m \alpha} V_{\beta}}{V_{l \alpha} V_{m \beta}-V_{l \beta} V_{m \alpha}} t_{s} \\
& t_{s h}=2(1-\alpha) \frac{V_{m \beta} V_{\alpha}-V_{m \alpha} V_{\beta}}{V_{l \alpha} V_{m \beta}-V_{l \beta} V_{m \alpha}} t_{s} \\
& t_{m}=\alpha \frac{V_{l \alpha} V_{\beta}-V_{l \beta} V_{\alpha}}{V_{l \alpha} V_{m \beta}-V_{l \beta} V_{m \alpha}} t_{s} \\
& t_{0}=t_{s}-t_{l}-t_{m}-t_{s h}
\end{aligned}
$$

Where, $\alpha=\frac{t_{l}}{t_{l}+t_{s h} / 2}$ generally taken as $\alpha=\frac{2}{3}$

$V_{l}=V_{l \alpha}+\mathrm{j} V_{l \beta}$

$V_{m}=V_{m \alpha}+\mathrm{j} V_{m \beta}$

$V_{s h}=\frac{V_{l}}{2}$

$V_{\text {ref }} t_{s}=V_{l} t_{l}+V_{m} t_{m}+V_{s h} t_{s h}+V_{0} t_{0}$

Where, $t_{l}$ is the dwell time for large vector,$t_{m}$ is dwell time for medium vector, $t_{s h}$ is dwell time for short vector, $t_{s}$ switching period for one cycle, $t_{0}$ is dwell time for zero vector.

Now for all the sectors switching sequence selected as

$$
V_{0}-V_{s h}-V_{m}-V_{l}-V_{m}-V_{s h}-V_{0}-V_{s h}-V_{m}-V_{l}-V_{m}-V_{s h}-V_{0}
$$

For sector one switching sequence will be given as considering one large vector, two medium vectors and two short vectors

$$
7,29,64,1,49,23,8,23,49,1,64,29,7
$$


Mapping

In DMC pulses can be obtained by mapping pulses of rectifier and inverter by following matrix and by ANDOR logic

$$
\left[\begin{array}{lll}
\mathrm{SAa} & \mathrm{SBa} & \mathrm{SCa} \\
\mathrm{SAb} & \mathrm{SBb} & \mathrm{SCb} \\
\mathrm{SAc} & \mathrm{SBc} & \mathrm{SCc} \\
\mathrm{SAd} & \mathrm{SBd} & \mathrm{SCd} \\
\mathrm{SAe} & \mathrm{SBe} & \mathrm{SCe} \\
\mathrm{SAf} & \mathrm{SBf} & \mathrm{SCf}
\end{array}\right]=\left[\begin{array}{cc}
\mathrm{S} 7 & \mathrm{~S} 8 \\
\mathrm{~S} 9 & \mathrm{~S} 10 \\
\mathrm{~S} 11 & \mathrm{~S} 12 \\
\mathrm{~S} 13 & \mathrm{~S} 14 \\
\mathrm{~S} 15 & \mathrm{~S} 16 \\
\mathrm{~S} 17 & \mathrm{~S} 18
\end{array}\right]\left[\begin{array}{lll}
\mathrm{S} 1 & \mathrm{~S} 3 & \mathrm{~S} 5 \\
\mathrm{~S} 2 & \mathrm{~S} 4 & \mathrm{~S} 6
\end{array}\right]
$$

\section{Result \& Discussion}

Parameters used for simulation purpose is listed in TABLE 1. In Fig 7. and Fig 8. (a) shows phase voltage (b) line voltage (c) speed and (d) torque with respect to time for modulation index 0.6 and 0.8 for direct matrix converter. Similarly Fig 9. and Fig. 10 shows same sequence of results for indirect matrix converter.

\begin{tabular}{|c|c|}
\hline Input supply & Vrms $=220 \mathrm{~V}, 50 \mathrm{~Hz}$ \\
\hline Input filter & $\mathrm{L}=125 \mathrm{mH} \quad \mathrm{C}=75 \mathrm{uF}$ \\
\hline Load parameters & $220 \mathrm{~V}, 3 \mathrm{HP}, 50 \mathrm{~Hz}$ \\
\hline Switching frequency & $5 \quad \mathrm{kHz}$ \\
\hline
\end{tabular}

\section{Table 1: Parameters for Simulation}

\section{A. Simulation Results for DMC}

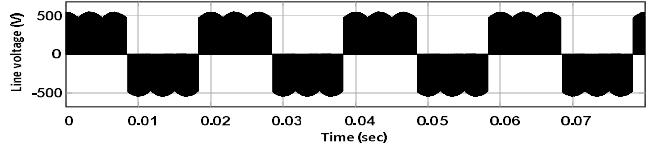

(a)

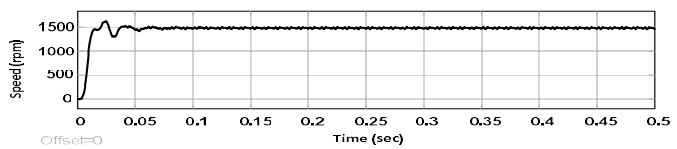

(c)

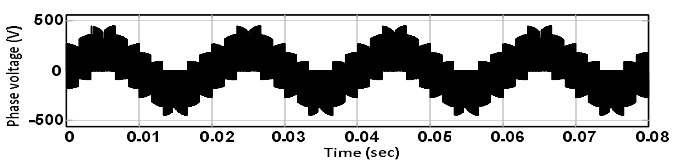

(b)

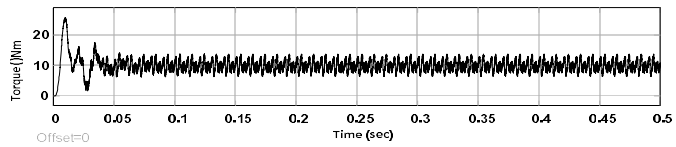

(d)

Fig 7: Output of three-to=six phase DMC at MI=0.6 (a) Line Voltage (b) Phase Voltage (c) Speed (d) Torque

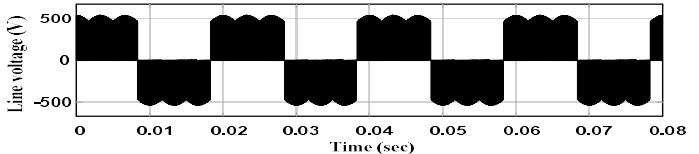

(a)

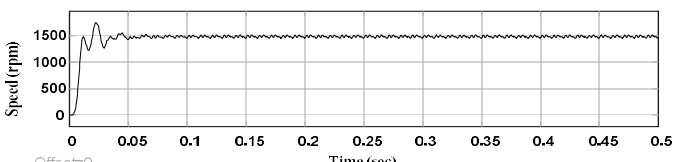

(c)

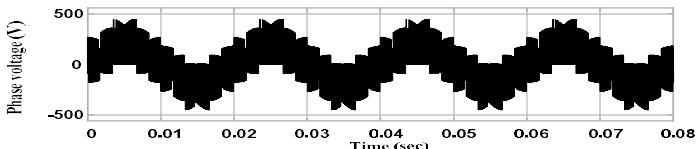

(b)

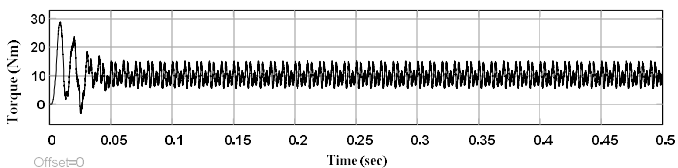

(d)

Fig 8: Output of three-to=six phase DMC at MI=0.8 (a) Line voltage (b) phase voltage (c) Speed (d) Torque 


\section{B. Simulation Results for IMC}

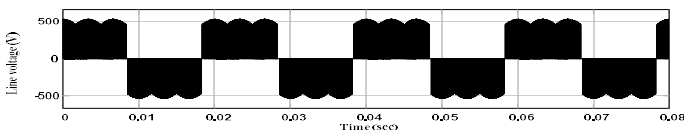

(a)

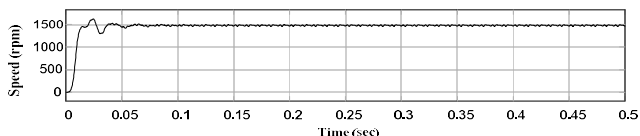

(c)

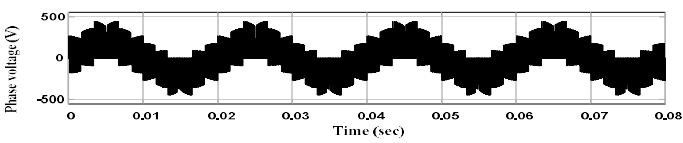

(b)

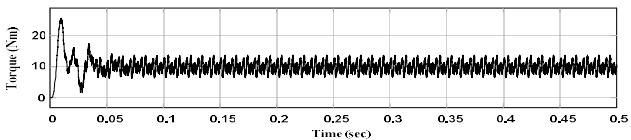

(d)

Fig 9: Output of three-to=six phase IMC at MI=0.6 (a) Line Voltage (b) Phase Voltage (c) Speed (d) Torque

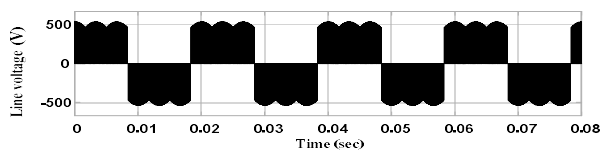

(a)

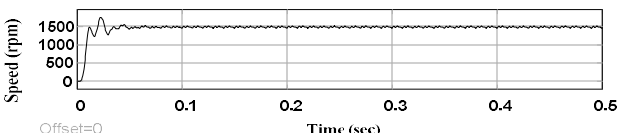

(c)

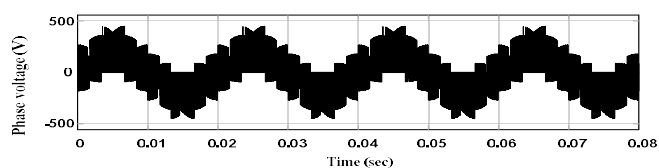

(b)

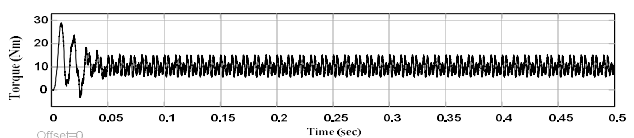

(d)

Fig 10: Output of three-to=six phase IMC at MI=0.8 (a) Line Voltage (b) Phase Voltage (c) Speed (d) Torque

\begin{tabular}{|c|c|c|c|c|}
\hline Parameters & \multicolumn{2}{|c|}{ Three-to-six phase DMC } & \multicolumn{2}{c|}{ Three-to-six phase IMC } \\
\hline Modulation Index & 0.6 & 0.8 & 0.6 & 0.8 \\
\hline Phase voltage (rms) & $114.3 \mathrm{~V}, \mathrm{THD}=121$. & $136.1 \mathrm{~V}, \mathrm{THD}=10$ & $114.3 \mathrm{~V}, \mathrm{THD}=12$ & $136.2 \mathrm{~V}, \mathrm{THD}=104.7$ \\
& $9 \%$ & $4.75 \%$ & $2.05 \%$ & $9 \%$ \\
\hline Line voltage $(\mathrm{rms})$ & $198.2 \mathrm{~V}, \mathrm{THD}$ & $236.6 \mathrm{~V}, \mathrm{THD}=9$ & $198 \mathrm{~V}$, & $236.7 \mathrm{~V}$, \\
& $=115.42 \%$ & $6 \%$ & $\mathrm{THD}=113.81 \%$ & $\mathrm{THD}=96.04 \%$ \\
\hline Speed $(\mathrm{rpm})$ & 1500 & 1500 & 1500 & 1500 \\
\hline Torque $(\mathrm{Nm})$ & 10 & 10 & 10 & 10 \\
\hline
\end{tabular}

Table 2: Simulation Results

\section{Conclusion}

Simulation analysis of both, three-to-six phase direct matrix converter and three-to-six phase indirect matrix converter fed to six-phase symmetrical induction motor are shown in above figures. Results are presented for modulation index 0.6 and 0.8 . From the results, it is clear that quality of output phase voltages and line voltages are same for both the converters for respective modulation indexes therefore both the converters can used to feed induction motor. In addition, speed vs time and torque vs time characteristics are studied.

\section{References}

1. E. Levi, R. Bojoi, F. Profumo, H. A. Toliyat and S.Williamson, "Multiphase induction motor drives - a technology status review," in IET Electric Power Applications, vol. 1, no. 4, pp. 489-516, July 2007.

2. P. W. Wheeler, "Multiphase induction motor drives," IET Chennai 3rd International on Sustainable Energy and Intelligent Systems (SEISCON 2012), Tiruchengode, 2012, pp. 1-1.

3. D. Casadei, G. Grandi, C. Rossi, A. Trentin and L. Zarri, "Comparison between back-to-back and matrix converters based on thermal stress of the switches," 2004 IEEE International Symposium on Industrial Electronics, Ajaccio, France, 2004, pp. 1081-1086 vol. 2

4. P. W. Wheeler, J. Rodriguez, J. C. Clare, L. Empringham and A. Weinstein, "Matrix converters: a technology review," in IEEE Transactions on Industrial Electronics, vol. 49, no. 2, pp. 276-288, April 2002 5. Ronald, Sharon D., A. Sheela and S. Josephin Mary. "Three Phase to Three Phase Direct Matrix Converter using SPWM Technique.” (2013). 
6. A. Trentin, P. Zanchetta, L. Empringham, L. de Lillo, P. Wheeler and J. Clare, "Experimental comparison between direct matrix converter and indirect matrix converter based on efficiency," 2015 IEEE Energy Conversion Congress and Exposition (ECCE), Montreal, QC, 2015, pp. 2580-2587

7. J. Rodriguez, M. Rivera, J. W. Kolar and P. W. Wheeler, "A Review of Control and Modulation Methods for Matrix Converters," in IEEE Transactions on Industrial Electronics, vol. 59, no. 1, pp. 58-70, Jan. 2012.

8. A. Benachour, E. Berkouk and M. O. Mahmoudi, "Study and implementation of indirect space vector modulation (ISVM) for direct matrix converter," 2015 3rd International Conference on Control, Engineering \& Information Technology (CEIT), Tlemcen, 2015, pp. 1-6.

9. L.Huber and D. Borojevic, "Space vector modulated three-phase to three-phase matrix converter with input power factor correction”, IEEE Trans. Ind. Appl., Vol. 31, no. 6, pp. 1234-1246, Nov./Dec. 1995

10. A. Iqbal, K. Rahman, R. Alammari and H. Abu-Rub, "Space vector PWM for a three-phase to six-phase direct AC/AC converter," 2015 IEEE International Conference on Industrial Technology (ICIT), Seville, 2015, pp. 1179-1184. 